\section{Os primeiros passos da Arqueologia da Arquitectura no âmbito do Instituto Português do Património Arquitectónico}

Maria M. B. De Magalhães Ramalho

Arqueóloga do Departamento de Estudos do Instituto Português do Património Arquitectónico

mramalho@ippar.pt

\section{Resumo}

Pretende-se, com este texto, traçar o percurso dos primeiros passos da afirmação da Arqueologia da Arquitectura no âmbito do Instituto Português do Património Arquitectónico (IPPAR), instituição a quem cabe a missão de preservar, salvaguardar e valorizar o património arquitectónico nacional. De facto, é possível constatar que, infelizmente, o conhecimento e a aplicação desta disciplina não só no IPPAR como em Portugal não teve ainda a divulgação necessária. Podemos afirmar que esta situação resulta não só de um desconhecimento geral da disciplina, como da situação algo peculiar da falta de interesse da maioria dos arquitectos portugueses pelas matérias relacionadas com o restauro arquitectónico. Por outro lado, sendo a arqueologia portuguesa deficitária em profissionais que se dediquem ao estudo de períodos mais recentes e reforçando-se a tendência da arqueologia de salvamento em detrimento da arqueologia de investigação, é notória a falta de motivação e sobretudo de tempo e meios económicos disponíveis para avançar com estudos desta natureza.

Apesar do IPPAR reflectir as dificuldades sentidas em termos nacionais, não podemos esquecer algumas iniciativas importantes bem como, o facto de ter sido graças à diligência das Direcções Regionais deste Instituto que se concretizaram os melhores trabalhos em Arqueologia da Arquitectura portugueses realizados no âmbito de vastos projectos de reabilitação de imóveis afectos.

Sendo clara a noção de que a Arqueologia da Arquitectura é o instrumento de análise mais rigoroso quando se trata de registar a biografia de um edifício e que, tal como hoje já existe, no âmbito do IPPAR, a consciência clara que qualquer intervenção ao nível do subsolo deverá implicar sempre um registo arqueológico prévio, torna-se agora necessário criar uma nova rotina que obrigue a que sempre que se programe uma intervenção ao nível do edificado, esta seja sempre precedida de um registo rigoroso, pois de outra forma continuaremos a assistir ao desaparecimento de informações únicas e irrepetíveis e ao nascimento de projectos de reabilitação sem qualquer fundamentação séria.

Palavras chave: Instituto Português do Património Arquitectónico, Arqueologia da Arquitectura, Biografia de um edifício.

\section{Abstract}

This text sets out to outline the first steps in the affirmation of Archaeology of Architecture within the scope of the Instituto Português do Património Arquitectónico (Portuguese Institute for the Architectural Heritage) - IPPAR, an institution whose goal is to preserve, safeguard and enhance our national architectural heritage. In fact, one can easily realise that, unfortunately, both in IPPAR and in Portugal this discipline has not yet been the object of a necessary divulgation. One could say that this is a result of a general unfamiliarity with this discipline, but also of a peculiar situation, namely the lack of interest, even contempt, that Portuguese architects show regarding those matters related to the rehabilitation of architecture. On the other hand, Portuguese archaeology lacking professionals devoted to the study of more recent periods and rescue archaeology getting stronger in detriment of investigation archaeology, the lack of motivation is notorious, and mainly the lack of time and financial means available to pursue any studies of this nature.

Although IPPAR reflects those difficulties felt in national terms, we cannot forget some significant initiatives, and also that it was thanks to the diligence of the IPPAR Regional Boards that some of the best works in the field of

Archaeology of Architecture were made possible, all within wide-ranging rehabilitation projects of buildings under the tutelage of the same Institute. Being clear the notion that Archaeology of Architecture is the most accurate instrument of analysis when it comes to recording the biography of a building, and the conscience that — as it already exists today within IPPAR — any intervention at subsoil level should always imply a previous archaeological record, it now becomes necessary to develop a new routine including a previous and accurate record whenever an intervention on a building is planned; otherwise we will keep on witnessing the disappearance of unique and unrepeatable information, and the forming of rehabilitation projects devoid of any serious grounding.

Key words: Institute for Architectural Heritage, Archaeology of Architecture, Biography of a building

\section{INTRODUÇÃO}

Quantos de nós, os que trabalhamos mais directamente com património arquitectónico, não nos deparámos já com verdadeiros enigmas nos edifícios que pretendemos reabilitar. São paredes que parecem não obedecer a qualquer lógica construtiva, vãos que surgem misteriosamente onde nada fazia suspeitar, rebocos e camadas de cal sobrepostas, níveis de pavimentos ou coberturas que nenhum documento assinalou, etc. etc., um infindável rol de supostas incongruências construtivas que não sabemos explicar.

Quantos de nós não fomos já levados também por um entusiasmo que nos assalta perante tais enigmas e, após uma apreciação mais ou menos ligeira, avançamos com explicações pouco fundamentadas que alguém, numa observação um pouco mais atenta, facilmente se permite desmontar, substituindo essa explicação por outra igualmente intuitiva, num esgrimir de argumentos que tantas vezes acabam por demonstrar que a realidade é bastante mais complexa. É assim que, após entusiasmados debates se concluiu que faltam dados para a compreensão da evolução ar-

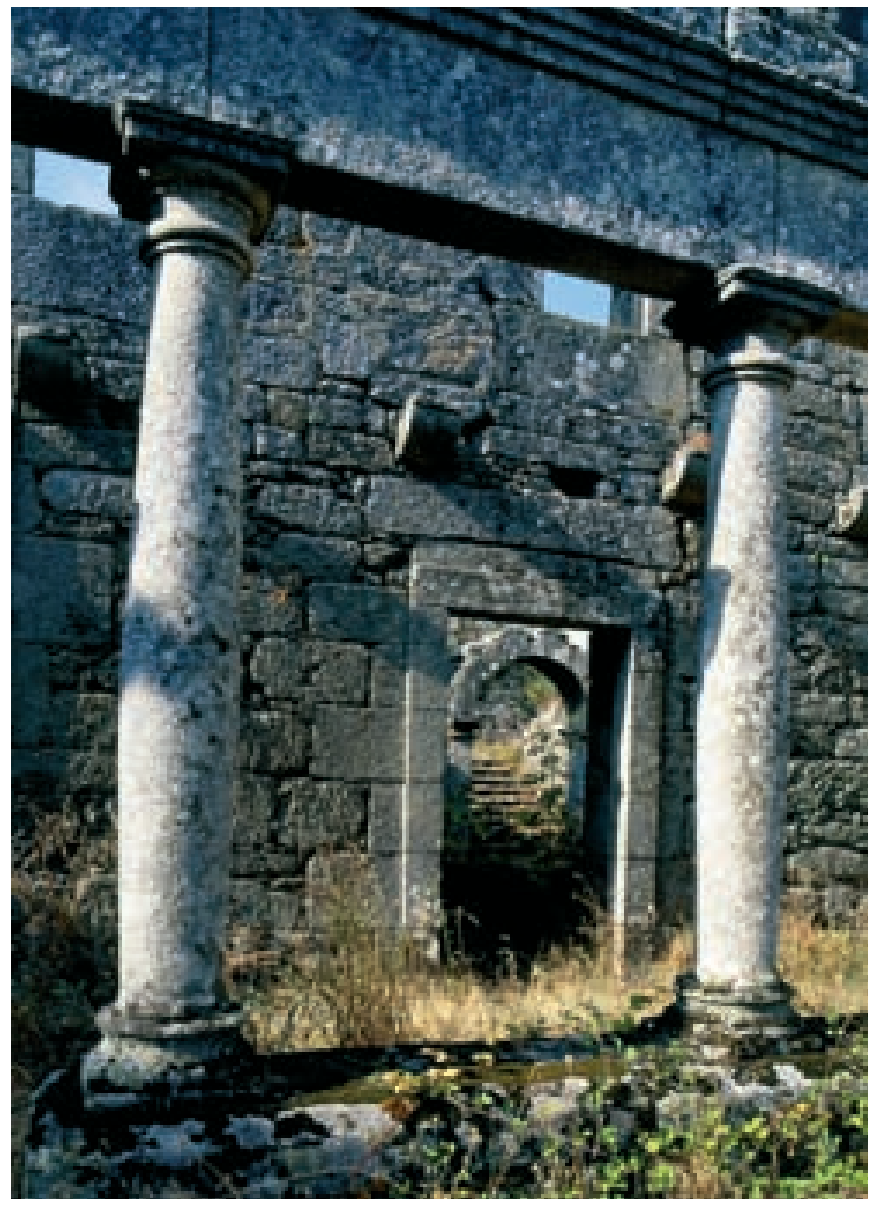

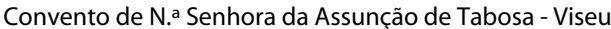
(Foto Henrique Ruas/IPPAR) 


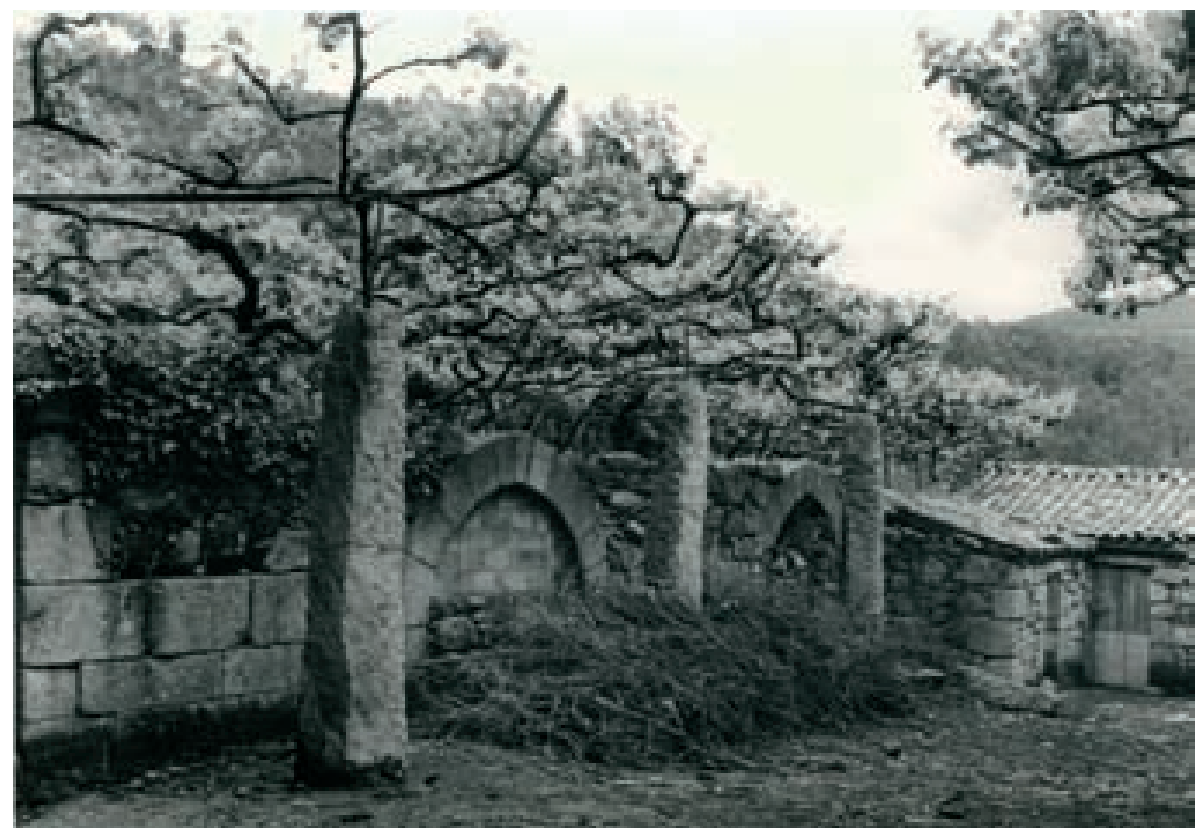

Igreja de São Bento de Ermelo - Viana do Castelo (Foto Arquivo IPPAR) quitectónica do edifício ou que a maior parte das situações não podem ser explicadas, considerando-se isso uma situação normal, fruto das vicissitudes por que passou o imóvel e acabando por se avançar com soluções pouco fundamentadas. É assim também que se decidem demolições, se alteram cotas de coberturas ou pavimentos, se modificam ou destroem sistemas hidráulicos, etc., etc.

Mas deixemos agora, por um momento, de olhar para o edifício e façamos um exercício de imaginação; suponhamos que sob os nossos pés, num local que sabemos ter sido intensamente ocupado ao longo dos séculos, um grupo de especialistas resolve abrir buracos a seu bel prazer, pondo a descoberto um conjunto de estruturas sem que para tal tenha sido utilizado um método coerente e sem a participação de uma equipa de arqueologia. Qual seria então o resultado obtido? Como explicar o emaranhado de vestígios incoerentes que vão surgindo, como interpretar os estratos diferenciados, como decidir o que fica e o que deve desaparecer? Ora foi exactamente isso que se passou durante anos em quase todas intervenções em edifícios históricos, por não se entender que estes necessitavam de uma abordagem especializada.

\section{A INTERVENÇÃO EM PATRIMÓNIO ARQUITECTÓNICO - BREVE HISTORIAL}

Desde pelo menos o final do século XIX que é usual as grandes intervenções nos chamados monumentos nacionais em Portugal serem apoiadas, quando o são, por explicações de carácter estilístico-comparativo, sendo convidados geralmente historiadores de arte que, compilando sobretudo in- formação documental, fornecem ao projectista a base para a elaboração do seu trabalho.

Não nos cabe a nós, neste curto texto, fazer o historial de toda a tradição de demolição/recriação/reinvenção efectuada durante anos nos nossos mais importantes edifícios históricos e de como essa tradição tem sido difícil de afastar. Julgo no entanto importante, para melhor compreendermos o que hoje sucede ao nível da abordagem destas questôes, nomeadamente no âmbito institucional, que recapitulemos brevemente quais as principais medidas tomadas desde a publicação do Alvará de D. João V, em 1721 onde, pela primeira vez, o Estado demonstrou que tipo de preocupações e que soluções previa para a salvaguarda do património arquitectónico nacional ${ }^{1}$.

No documento de 1721 é clara a noção de que a protecção do património histórico é um dever público e estatal, declarando-se, igualmente, que seriam penalizados todos aqueles que procedessem à destruição de antiguidades. Pela primeira vez também, surgem-nos indicações da necessidade de realização do inventário dos bens nacionais, mas sobretudo a noção importantíssima, e que nos centra no assunto que queremos abordar, alusiva à necessidade da redacção de memórias descritivas e respectivos registos gráficos dos edifícios. Infelizmente, apesar das boas intenções deste Alvará, na realidade o país não estava ainda devidamente preparado para que se aplicassem as medidas preconizadas. Mais tarde, o decreto de abolição das ordens religiosas,

\footnotetext{
1 Património Arquitectónico e arqueológico - informar para proteger (1994), p. 7.
} 
Sé Catedral do Porto durante as obras de restauro. Boletim da DGEMN n. ${ }^{\circ}$ 40-43, 1946

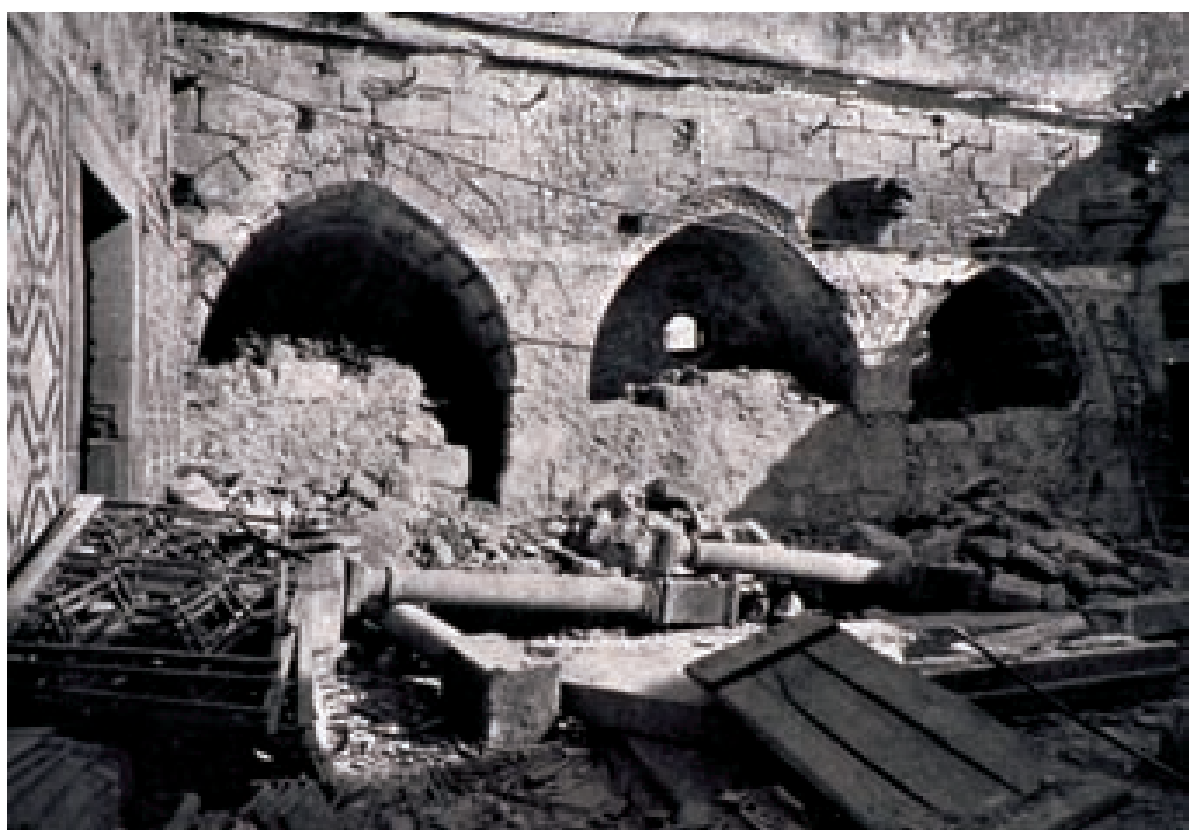

em 1834, com o consequente desmantelamento e pilhagem dos edifícios, irá servir para que, uma vez mais, a tomada de consciência dos valores que se perdiam e a urgência em criar medidas que estancassem a destruição que estava a ser prepretada, fossem encaradas novamente a nível estatal. Apesar disso, as poucas iniciativas que foram tomadas, quer no respeitante à necessidade de se efectivar a inventariação do património mais relevante ou de se proceder a operaçōes de restauro, não tiveram praticamente impacto, perante o universo alargado de problemas a resolver, denotando quer ao nível das dotaçóes orçamentais, como ao nível de programas governativos, que a Salvaguarda do Património Nacional, na realidade, não representava uma preocupação séria num país de população pouco instruída e onde a maioria dos técnicos dos ministérios não possuíam a formação adequada. No entanto, e apesar da falta de preparação, não foi necessário esperar muito tempo para que se procedessem a obras de vulto nos edifícios consideradas de "primeiríssima ordem» tais como a Torre de Belém, Mosteiro dos Jerónimos ou Sé de Lisboa, denotando, também, que o pouco que se fazia se centrava sobretudo em Lisboa.

A pouco e pouco, associações de carácter privado, empenhadas no estudo e salvaguarda dos monumentos, tais como a Real Associação de Architectos Civis e Archeologos Portugueses onde se reuniram algumas das figuras mais capacitadas e informadas, sobretudo no âmbito da arqueologia medieval cristã, foram adquirindo determinadas competências, acabando mesmo por influenciar positivamente as medidas governamentais que foram sendo tomadas, culminando com a criação, em 1882, da primeira estrutura direccionada para a defesa e intervenção em património arquitectónico, a «Comissão dos Monumentos Nacionais». É então que, uma vez mais, volta a ser referida a necessidade de proceder ao registo das plantas e alçados dos edifícios, adquirindo o restauro um novo impulso, sobretudo a partir da última década de oitocentos.

Com o aparecimento de intervenções diversificadas quer em edifícios religiosos como militares surgiram, também, os ecos dos primeiros confrontos de ideias sobre os projectos executados, destacando-se um pequeno conjunto de personalidades que permanecem desconhecidas da maioria de nós e que urge estudar pela importância que adquiren no entendimento da evolução do pensamento patrimonialista português, permitindo, por exemplo, que se compreenda que afinal as metodologias aplicadas foram também questionadas na época. Como exemplo refira-se a figura de Gabriel Pereira, funcionário da referida Comissão e um dos poucos que, à época, se apercebeu dos verdadeiros problemas que se colocavam nas intervenções de restauro:

"Com a teoria de Viollet-le-Duc não há saber ou engenho capazes de salvar as obras de arte do arbitrio; e o arbitrio é nesse caso uma falsificação, uma ratoeira aos vindouros e mentira aos contemporâneos' ${ }^{2}$.

Efectivamente, em Portugal, como na maioria dos países europeus, a influência de Viollet-le-Duc fez-se sentir de uma forma avassaladora com o prejuízo, no caso do nosso país, de não ter sido acompanhada das componentes teóri-

\footnotetext{
2 Custódio, Jorge (1993).
} 


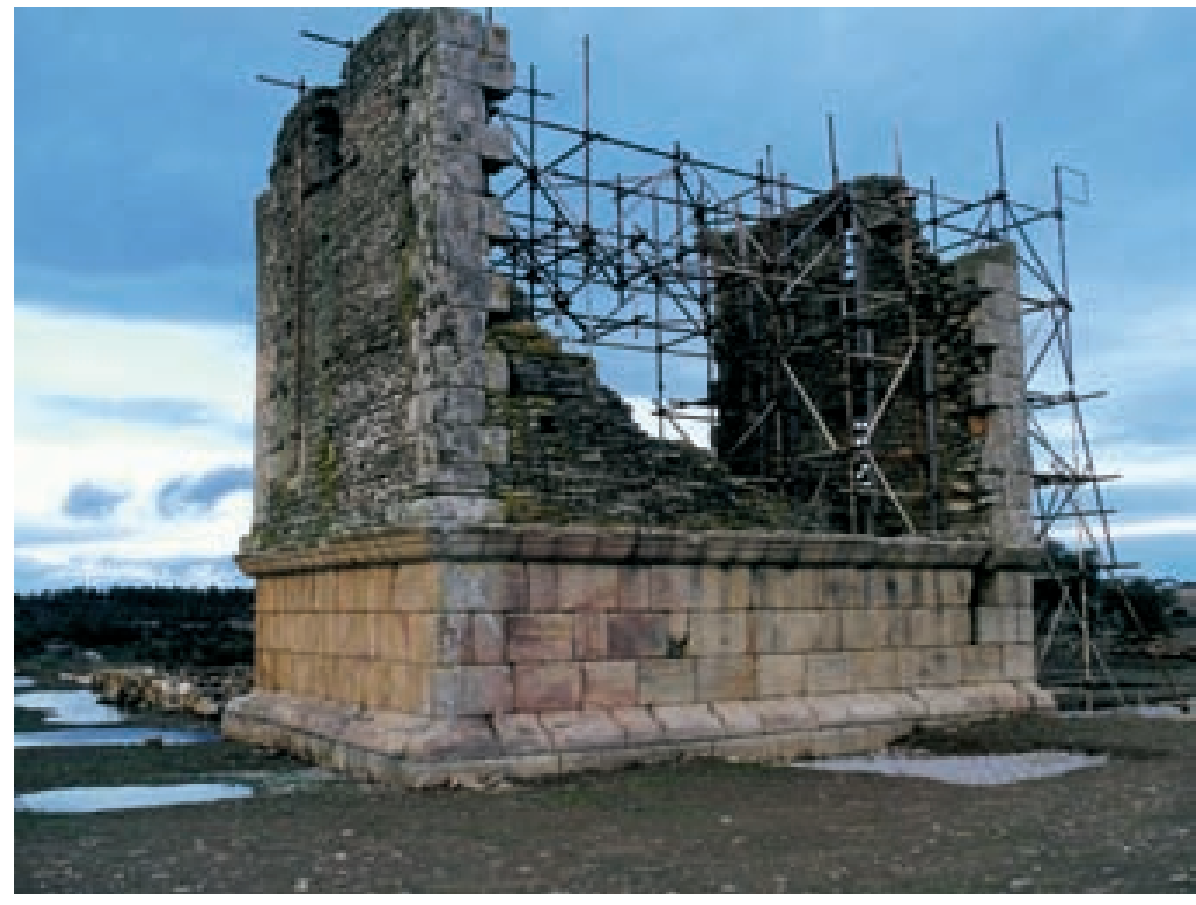

Torre de Almofala - Guarda. (Foto A. Mimoso/IPPAR) cas e práticas de estudo e registo que este arquitecto preconizava. Contrariamente ao defendido por le-Duc, quando se procedia a uma intervenção, além dos registos fotográficos que são ainda hoje os mais importantes testemunhos de como eram estes edifícios, pouco ou nenhuma recolha histórica se efectuava, limitando-se, a maior parte das vezes a compilaçóes de bibliografia conhecida, sendo raros os desenhos ou levantamentos rigorosos do edificado. Consultando os processos existentes nos arquivos verifica-se, igualmente, que a argumentação utilizada para justificar as opções tomadas se reduzia a curtos parágrafos, denotando a falta de preparação dos técnicos envolvidos fazendo com que hoje o impacto das falsificações de que falava Pereira, seja uma triste realidade.

Em 1929 é criada a Direcção-Geral de Edifícios e Monumentos Nacionais (DGEMN), na alçada do Ministério das Obras Públicas. A partir desse momento, o ideal político do Estado Novo rapidamente se confunde com as novas práticas de restauro que doravante passam a ser encaradas como uma verdadeira missão patriótica. $\mathrm{O}$ culto da Idade Média, exacerbado pelo Salazarismo como época gloriosa, faz-se sentir nas opções tomadas na maioria das intervenções arquitectónicas que, sistematicamente, ignoraram as denominadas "excrescências» dos períodos que se seguiram, destruindo ou camuflando para sempre a longa e rica história da maior parte dos nossos edifícios monumentais, deixando para a posteridade um rol de estruturas despidas, mutiladas e transfiguradas de que apenas os registos fotográficos e os Boletins editados por essa Instituição são testemunhas. Paradoxalmente, apesar da participação de Portu- gal na redaç̧ão da Carta de Veneza de 1964 onde, como todos sabemos, se repudiam abertamente este tipo de metodologias, praticamente nada foi alterado, continuando a verificar-se, ao longo das década de 70 e 80 , a aplicação de métodos muito semelhantes, tal como é hoje possível verificar nos processos e obras publicadas.

\section{A INTERVENÇÃO EM PATRIMÓNIO ARQUITECTÓNICO - ALGUNSTÓPICOS}

A criação, em 1980, do Instituto Português do Património Cultural (IPPC), no rescaldo das movimentações resultantes da Revolução de Abril, procurou dar resposta, mas agora no âmbito da Cultura, aos inúmeros desafios que a Salvaguarda do Património colocava. Esta Instituição, que mais tarde dará origem ao IPPAR, irá não só assumir uma série de valências relativas ao património arquitectónico e arqueológico, como em relação à salvaguarda dos bens artísticos, bibliográficos, etnográficos, etc. Dada a dimensão da tarefa, foi necessário, em 1992, autonomizar uma série de competências dando origem a diversos institutos entre os quais o IPPAR - Instituição a quem foram definidas as atribuições «de salvaguarda e valorização de bens que, pelo seu interesse histórico, arqueológico ou paisagístico, integrem o património cultural arquitectónico e arqueológico do Pais»”.

Desde estão, com a afirmação do IPPAR como promotor de obras surgiram também algumas das principais

${ }_{3}^{3}$ DECRETO-LEI n.o 106-F/92. D. R. I Série. 126 (92-6-1), 2648 (28). 
polémicas que continuam a marcar a política patrimonial a nível estatal, nomeadamente em relação ao papel que caberá a cada uma das Instituições que mais intervêm (IPPAR e DGEMN) na autorização, coordenação e fiscalização das intervenções em património classificado.

Se olharmos a legislação produzida mais tarde, em 1997, quando é aprovada a nova orgânica do IPPAR, verificamos que cabe a este Instituto coordenar a nivel nacional as acçôes a levar a cabo sobre património cultural imóvel (... $)^{4}$, ou seja, que qualquer obra em edifícios de valor arquitectónico está obrigatoriamente sujeita a parecer do IPPAR. Também nesta lei surge a referencia à obrigatoriedade do IPPAR e da DGEMN elaborarem, anualmente, um programa de intervenções, situação que, até o momento, não tem sido posivel concretizar.

Ainda na lei orgânica do IPPAR se regista que são atribuições suas a realização de obras de construção, ampliação, remodelação, conservação e restauro (...) em bens imóveis 5 . Por outro lado, na lei orgânica da DGEMN ${ }^{6}$, é também assinalado que compete a esta Instituição o planeamento, concepção e execução das acçôes de valorização, recuperação e conservação dos bens imóveis classificados não afectos ao IPPAR'. Resumidamente, temos duas instituiçôes com algumas competências idênticas e cujo objectivo deverá ser a colaboração e discussão de políticas de intervenção em património arquitectónico.

No entanto, apesar de algumas divergências, em termos gerais, parece ser indiscutível que hoje em Portugal os estudos que se fazem sobre património arquitectónico nas várias Instituições com responsabilidades na matéria, são cada vez mais numerosos, aprofundados e diversificados, nomeadamente ao nível dos materiais construtivos, destacando-se o excelente trabalho desenvolvido por algumas equipas de técnicos de conservação e restauro. Por outro lado, pelo menos no âmbito das iniciativas da responsabilidade do IPPAR, o tempo de intervenção nos edifícios, como é natural em estruturas complexas desta natureza, é cada vez mais alargado, contando habitualmente com intervenções prévias de arqueologia. No entanto, e apesar desta evolução positiva, o mesmo não se tem aplicado (salvo raras excepçôes), ao estudo do edifício em si, nomeadamente nos cuidados a ter em relação aos registos prévios a qualquer tipo de intervenção.

É neste tipo de situações que a Arqueologia da Arquitectura surge como um desafio inovador ao propor abordar

\footnotetext{
${ }^{4}$ Decreto-Lei n.o 120/97. D. R. I Série. 113 (97-5-16), 2422.

5 Ibidem, p. 2422.

${ }^{6}$ Decreto-Lei n.o 284/93. D. R. I Série. 193 (93-8-18), 4406.

7 Ibidem, p. 4407.
}

o edifício em toda a sua complexidade, compreender a sua história pessoal única e irrepetível de uma forma integrada, conjugando os dados históricos, com o dados fornecidos pelos materiais e técnicas construtivas, os estudos de patologias, comportamentos estruturais etc. bem como, no caso de se efectuarem escavações, os dados da arqueologia.

A Arqueologia da Arquitectura possibilita assim uma completa renovação metodológica no modo de abordar o património construído, pois através da análise estratigráfica, que até recentemente era apenas utilizada pelos arqueólogos, é possível alcançar a mais completa biografia do edifício, permitindo alcançar resultados de tal forma importantes que têm conseguido suscitar, entre os mais diversos técnicos, uma adesão considerável, bem patente nos últimos encontros sobre Arqueologia da Arquitectura, nomeadamente em Espanha, onde esta disciplina tem vindo a adquirir especial relevância. Trata-se pois de uma metodologia que, estamos em crer, possuiu a capacidade de responder às necessidades de todos aqueles que mais directamente se relacionam com o estudo ou intervenção em património arquitectónico, nomeadamente arqueólogos, historiadores de arte e arquitectos, sobretudo entre as novas gerações que, sem dúvida, estarão mais preparadas e empenhadas em lidar com as possibilidades oferecidas pelas novas tecnologias, instrumentos fundamentais para o avanço futuro desta especialidade.

\section{ARQUEOLOGIA DA ARQUITECTURA NO ÂMBITO DO IPPAR}

Podemos referir que, em termos institucionais, tem sido no seio do IPPAR que a Arqueologia da Arquitectura tem dado os seus primeiros passos, apesar de, infelizmente, estarmos longe de ser uma matéria conhecida pela maioria do seu corpo técnico. Gostaríamos, neste breve texto, referir que foi sobretudo graças à iniciativa de algumas das Direcçôes Regionais do IPPAR que se concretizaram os melhores trabalhos em Arqueologia da Arquitectura realizados até ao momento em Portugal, nomeadamente no âmbito de projectos de reabilitação de imóveis afectos.

\subsection{Intervenções realizadas ou em curso}

O edifício onde pela primeira vez foi efectuada a análise estratigráfica exaustiva dos paramentos foi a igreja de São Gião da Nazaré, intervenção da iniciativa da Direcção Regional de Lisboa e do Departamento de Estudos do IPPAR. Aqui, uma equipa do Consejo Superior de Investigaciones Científicas de Madrid ${ }^{8}$, teve a oportunidade de recolher

\footnotetext{
${ }^{8}$ Equipa liderada por Luís Caballero Zoreda onde participaram Maria Ángeles Utero, Fernando Arce, Carlos Cauce, Luís Fontes, Maria de Magalhães Ramalho e Mário Cruz.
} 


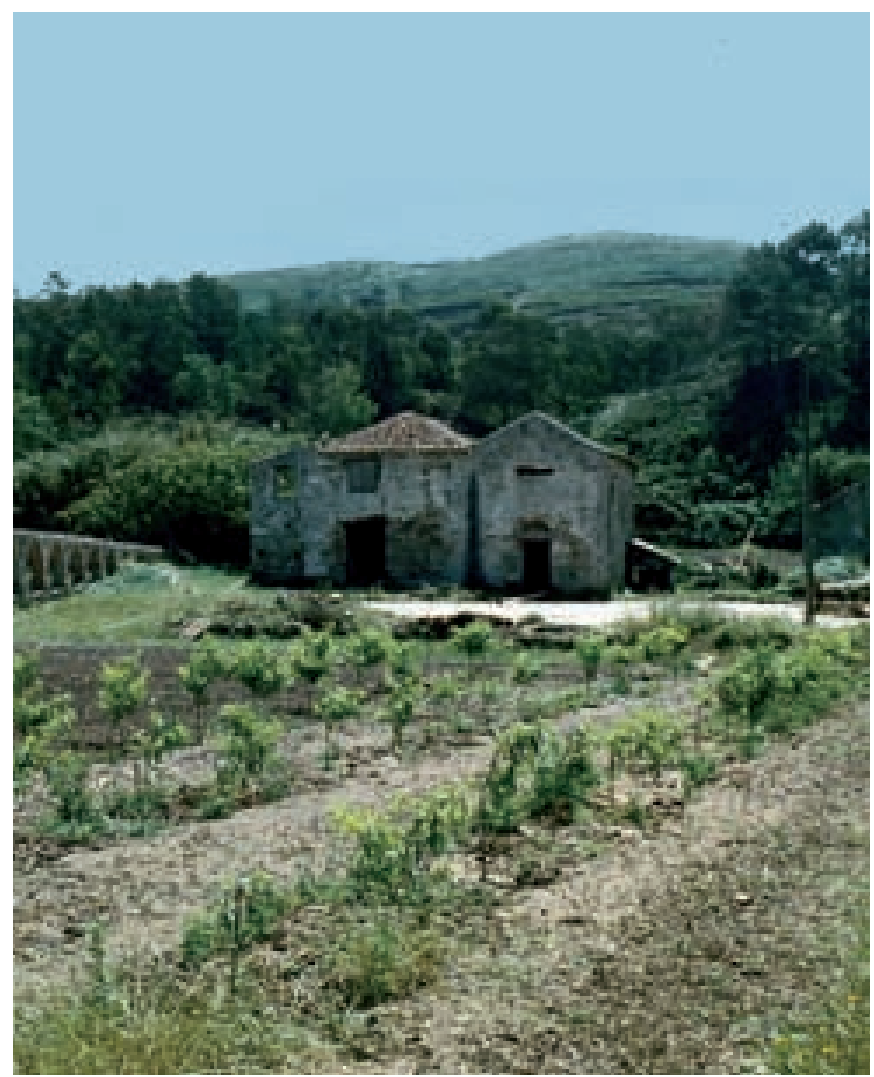

Igreja de S. Gião da Nazaré em 1992 (Foto Arquivo IPPAR)

importantes informaçôes e apresentar um extenso relatório que serviu, juntamente com os dados históricos 9 e o resultados das pesquisas arqueológicas ${ }^{10}$, para nos dar uma visão bastante mais aproximada da evolução deste monumento que tantas polémicas já suscitou, convertendo-se, simultaneamente, no instrumento base do projecto de reabilitação arquitectónica que se pretende implementar nos próximos anos, assim haja apoio financeiro que o possa sustentar.

Outra das iniciativas que considero marcante para a afirmação da Arqueologia da Arquitectura em Portugal nasceu igualmente da iniciativa do IPPAR, através da Direcção Regional do Porto. Trata-se, neste caso, de uma intervenção da responsabilidade da Universidade do Minho ${ }^{11}$ no Mosteiro de Rendufe, seguindo a estratégia já anteriormente ensaiada noutros monumentos, nomeadamente no Mosteiro de Tibães.

Também no Convento de São Francisco de Santarém, na Casa Rural existente nas ruínas arqueológicas de Milreu no Algarve ${ }^{12}$ e, mais recentemente, no Castelo de Castelo

\footnotetext{
9 Trabalho desenvolvido por Pedro Penteado.

10 Intervenção coordenada por Luís Fontes da Universidade do Minho.

11 Equipa coordenada por Luís Fontes.

12 Estas intervenções foram coordenadas pela signatária deste artigo em 1996 e 2001-2002 respectivamente.
}

de Vide ${ }^{13}$, um conjunto de técnicos do IPPAR têm vindo a efectuar algumas tentativas de utilização deste método, mas enfrentando as dificuldades de se tratar de iniciativas com parcos recursos, prazos muito curtos e levantamentos gráficos algo deficitários para os quais, não tem sido possível reunir o mínimo de colaboradores indispensáveis em trabalhos desta natureza, impossibilitando, pelo menos até ao momento, que se alcance um conhecimento exaustivo dos edifícios em questão. Ainda no âmbito das intervenções promovidas pelo IPPAR, nomeadamente no Mosteiro de Santa Clara-a-Velha ${ }^{14}$, nas Termas romanas de São Pedro do Sul ${ }^{15}$ e no Mosteiro de Alcobaça ${ }^{16}$, foram efectuados registos rigorosos dos alçados e diferentes estudos do edificado, mas onde também ainda não foi possível realizar uma completa leitura estratigráfica de todo o conjunto edificado.

No âmbito do programa Nacional de Investigação Científica, Desenvolvimento e Inovação Tecnológica de Espanha, encontra-se em fase de elaboração um projecto intitulado "Arqueologia da Arquitectura Altomedieval nas Astúrias, Extremadura e Portugal» coordenado pelo Dr. Luís Caballero, no qual o IPPAR foi convidado a participar. Integrado neste projecto, encontra-se em fase de conclusão o primeiro estudo de arqueologia da arquitectura sobre a Sé Catedral de Idanha-a-Velha, edifício sobejamente discutido pelas dúvidas que coloca a pesar de ser possível, sobretudo ao nível dos paramentos exteriores, obter alguma informação importante do ponto de vista estratigráfico, nunca foi convenientemente estudado.

Neste momento, encontra-se também em fase inicial o projecto da iniciativa da Câmara Municipal de Lisboa destinado à recuperação de uma das Torres da muralha fernandina de finais do século XIV, a designada Torre da Pela, situada no Largo do Martim Moniz ${ }^{17}$. O IPPAR associou-se a este projecto pretendendo-se que, brevemente, seja possível concretizar um estudo exaustivo deste interessante vestígio, fazendo dele um exemplo de como se podem conseguir bons resultados conjugando esforços de diferentes entidades. Esta iniciativa parece-nos sobretudo importante do ponto de vista da formação, pois será a primeira vez que um grupo de técnicos,

\footnotetext{
13 Projecto de recuperação do antigo paiol do Castelo da autoria do arquitecto Teotónio Pereira e associados. Coordenação pelo IPPAR do arquitecto João Pires da Direcção Regional de Évora.

${ }_{14}$ Intervenção da responsabilidade do arqueólogo Artur Corte-Real da Direcção Regional de Coimbra do IPPAR.

15 Intervenção arqueológica e análise do conjunto edificado dirigida por Helena Frade, arqueóloga da Direcção Regional de Coimbra do IPPAR.

${ }^{16}$ Intervenção e registos da responsabilidade da arqueóloga Ana Nunes da Direcção Regional de Lisboa do IPPAR.

17 Coordenação científica das escavaçôes arqueológicas bem como do projecto de arqueologia da arquitectura da responsabilidade da arqueóloga Manuela Leitão do Museu da Cidade-Câmara Municipal de Lisboa.
} 


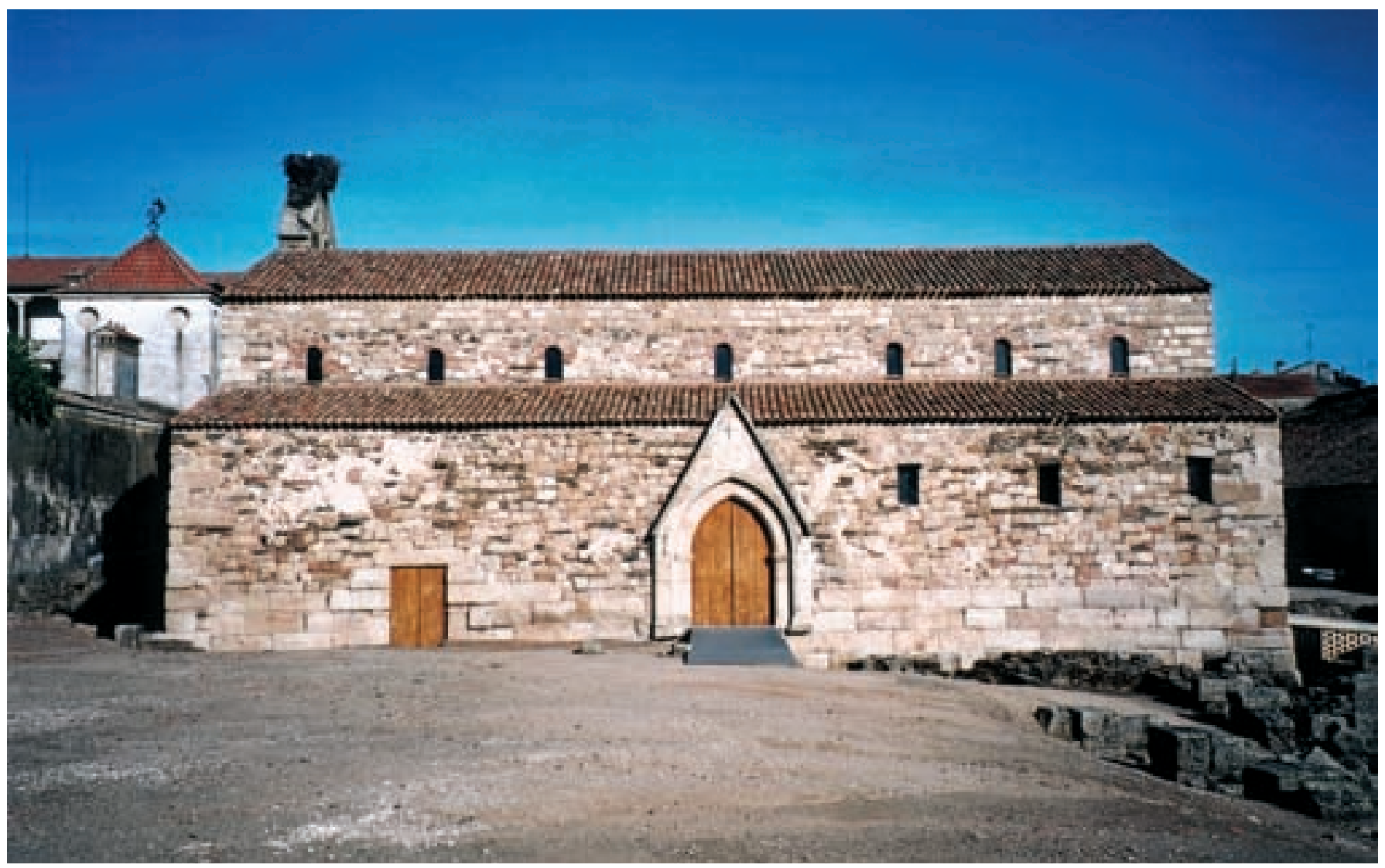

Catedral de Idanha-a-Velha (Foto M. Ramalho/IPPAR)

incluindo uma empresa de arqueologia levará a cabo um estudo de Arqueologia da Arquitectura em Lisboa, possibilitando que, no futuro, seja possível avançar com novos projectos.

No capítulo da divulgação, área essencial para se avançar com a afirmação desta disciplina em Portugal, o IPPAR teve o ensejo de promover, em 1999 e em 2005, um conjunto de conferências proferidas por um grupo de especialistas com currículo afirmado na área, resultando assim na primeira apresentação pública em Portugal sobre o método, seus objectivos e capacidades, bem como alguns resultados já obti$\operatorname{dos}^{18}$. Refira-se que esta primeira experiência contou desde logo com uma ampla assistência onde se incluíam técnicos de diferentes especialidades.

\footnotetext{
18 Conferências "Património arquitectónico - análise arqueológica da arquitectura e métodos de registo». Palácio Nacional da Ajuda, 27 de Abril de 1999. Estiveram presentes os arqueólogos Luis Caballero Zoreda e Agustin Azkarate e os arquitectos Leandro Cámara e Pablo Latorre.

Conferências «Património Arquitectónico. Registro, Interpretação e criterios de Intervenção». Museu Nacional de Etnologia (Lisboa), 16 set. 2005. Foram conferencistas os arqueólogos Luis Caballero, Luis Fontes e os arquitectos Francesco Doglioni, Antoni González, José Aguiar, Fernando Vegas e Camilla Mileto
}

Também na sua publicação periódica, a Revista Estudos-Património, o IPPAR tem procurado editar alguns artigos dedicados quer à divulgação deste método, como à apresentação de algumas experiências nomeadamente efectuadas fora do País, esperando que, brevemente, possamos alargar esta temática tornando-a mais consistente em termos editoriais.

Ainda dentro das iniciativas que se prendem com a divulgação, foi possível no âmbito do protocolo existente entre o IPPAR e a Universidade Nova de Lisboa a realização de um Seminário no Curso de História de Arte onde, em dois anos consecutivos, tivemos a oportunidade de preparar uma sessão intitulada Arqueologia e Arquitectura - métodos de registo. Ainda que de uma forma bastante sintética, pretendeu-se sobretudo sensibilizar os alunos para as potencialidades do método arqueológico aplicado aos edifícios históricos e as questôes que se colocam nas intervençôes em património arquitectónico.

\section{PROPOSTAS PARA O FUTURO}

Apesar das iniciativas que acabámos de enumerar, é fácil constatar que, infelizmente, o conhecimento e a aplicação da Arqueologia da Arquitectura não teve ainda a implan- 


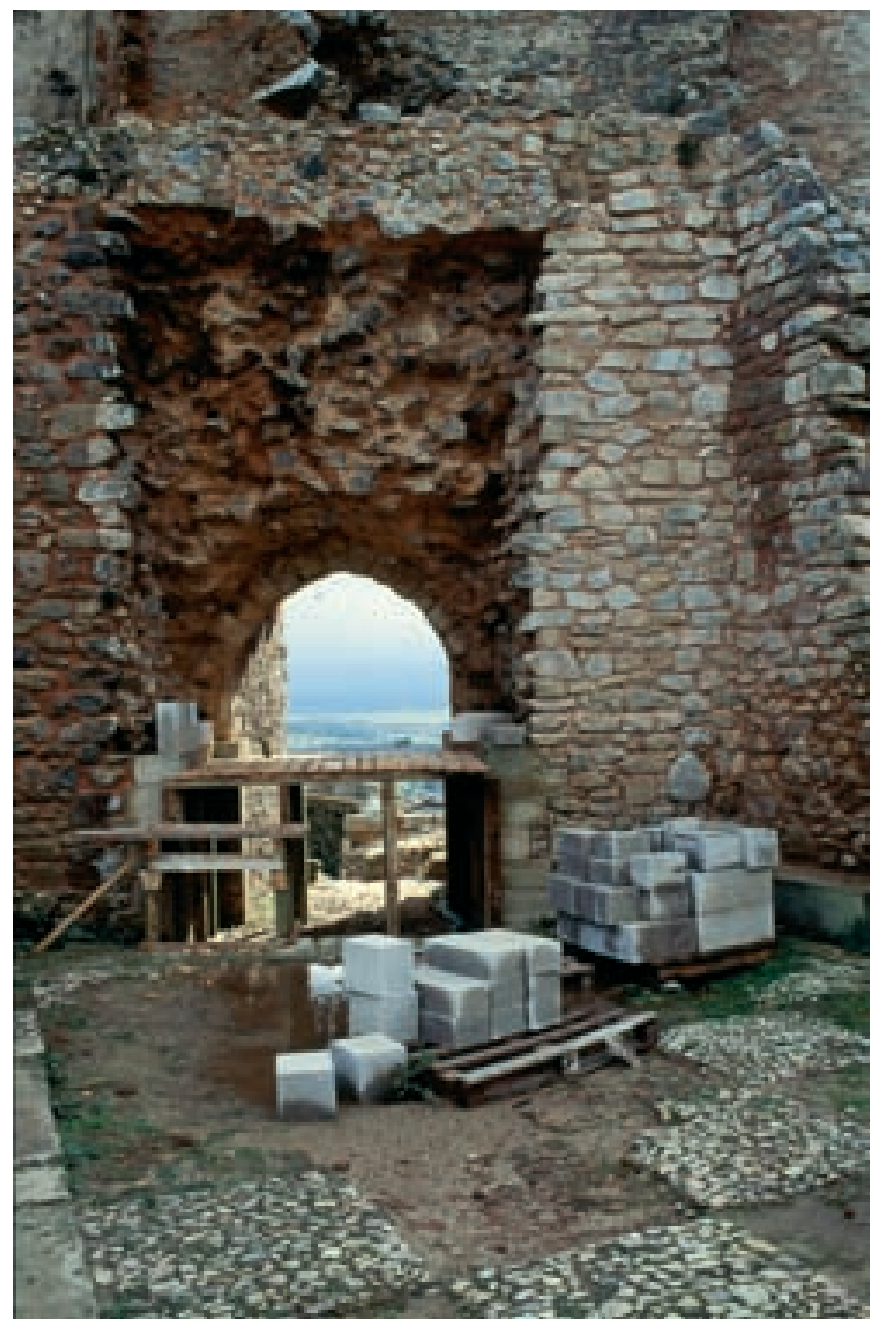

Fase de obra no Castelo de Castelo Rodrigo - Guarda (Foto Arquivo IPPAR)

tação necessária, particularmente devido à falta de conhecimento do método e à carência de técnicos com a devida formação.

Por outro lado, podemos afirmar que esta condição resulta também da situação algo peculiar da falta de interesse, diria mesmo desprezo, da maioria dos arquitectos portugueses pelas matérias relacionadas com o restauro arquitectónico, resultado sem dúvida da prática universitária tão carente em alternativas na área do património. Da mesma forma, sendo a arqueologia portuguesa deficitária em profissionais que se dediquem ao estudo de períodos mais recentes e reforçando-se a tendência da arqueologia de salvamento em detrimento da arqueologia de investigação, é notória a falta de motivação e sobretudo de tempo e meios económicos para avançar com estudos desta natureza.

Todos sabemos também como por vezes é difícil o diálogo entre arqueólogos e arquitectos, e como permanece ainda a convicção, na mente de muitos, que existem fronteiras nítidas quando se trata de levar a cabo uma inter- venção de recuperação, reservando-se aos arqueólogos a cota zero enquanto o resto, se destina primeiro aos historiadores de arte e depois aos arquitectos. Estamos em crer que esta é, na realidade, a opção mais confortável, ou seja, nada melhor para o arqueólogo do que olhar só para baixo e ao arquitecto ser permitida a liberdade de criar a partir das velhas paredes, sem que nem um nem outro interfira no desenvolvimento dos trabalhos. Tendo em conta os "vícios» criados e a complexidade a que normalmente estão associadas intervençóes desta natureza, sobretudo quando o projecto é de grande impacto, dificilmente será possível inverter as mentalidades, a não ser que exista, da parte do dono da obra, uma noção clara de que o diálogo é necessário e que seja ele o primeiro a promovê-lo. No entanto, volto a frisar, de nada valerá o diálogo e as boas intenções, se não existirem técnicos capacitados para responder aos desafios e necessidades criadas.

Com isto queria sobretudo acentuar a necessidade real de se avançar um pouco mais nas políticas de intervenção, compreender aquilo que os edifícios encerram de único e colocar a importância histórica do imóvel que se pretende reabilitar no centro da discussão e não o projecto de recuperação, como tantas vezes acontece.

Parecendo-nos clara a noção de que a Arqueologia da Arquitectura é o instrumento de análise mais rigoroso que possuímos até ao momento, quando se trata de registar a biografia de um edifício e que, tal como hoje já existe, no âmbito da maior parte das instituições, a consciência clara que qualquer intervenção ao nível do subsolo deverá implicar sempre um registo arqueológico prévio, torna-se agora necessário criar uma nova rotina que obrigue a que sempre que se programe uma intervenção ao nível do edificado, esta seja precedida de um registo rigoroso, pois de outra forma continuaremos a assistir ao desaparecimento de informaçōes únicas e irrepetíveis e ao nascimento de projectos de reabilitação sem qualquer fundamentação séria.

Com o que foi exposto anteriormente não queremos criar a ideia que se pretende reduzir a capacidade de intervir nos edifícios, mas antes criar a consciência, nos responsáveis pelos projectos, que se vai interferir numa construção estratificada e, como tal, deverá ser estudada tão exaustivamente quanto possível de forma a que esse estudo acabe por se converter ele mesmo no sustentáculo do projecto que se pretende implementar, fornecendo pistas, ideias, soluções que certamente serão muito mais estimulantes do que partindo de uma estrutura desconhecida, onde os imprevistos representam tantas vezes prejuízos avultados.

Uma das formas para que se possa inverter a situação actual, será, sem dúvida, através da formação. Assim, o papel das universidades poderá converter-se num dos factores 
primordiais para que esta mudança se verifique, apostando numa formação mais aberta e virada para as verdadeiras necessidades da sociedade actual, apostando numa maior flexibilidade dos currículos, facultando-se, por exemplo, a transversalidade dos cursos de arquitectura, arqueologia, geologia, história, etc.

Outro dos aspectos fundamentais a ter em conta é que a própria legislação deveria contemplar uma noção mais alargada do património arquitectónico ${ }^{19}$, de forma a reforçar a ideia, no seio da sociedade, que o valor patrimonial de um determinado edifício e o impacto por ele criado em termos territoriais é mais amplo do que geralmente lhe é atribuído, criando desta forma também, julgamos nós, um elo mais forte entre os monumentos e as próprias comunidades onde estes se inserem ${ }^{20}$.

No entanto, sabemos que o facto de existirem leis bem elaboradas, não significa que a situação se altere substancialmente, mas deverão ser antes os próprios agentes responsáveis pela Salvaguarda do património construído, sobretudo os técnicos ao nível central e autárquico, que possam ver no conhecimento profundo do edifício, uma mais valia para o seu trabalho.

Concluindo, considero que apesar da evolução dos últimos anos, em termos de conhecimento histórico dos edifícios, e os cuidados cada vez mais notórios nas ciências e técnicas aplicadas, julgo que muito há ainda a fazer. A descoordenação que muitas vezes se verifica não só entre entidades responsáveis pelo património edificado, como entre as equipas das diversas especialidades; a insuficiente formação tanto de arqueólogos como de arquitectos em aspectos directamente relacionados com as formas de registo e análise do edificado, são factores a ter em conta, bem como a ausência de análise crítica do trabalho e falta de um verdadeiro corpus teórico que enquadre este tipo de actividades.

De qualquer forma, para não terminar num tom demasiado negativo, parece-nos estarem criadas algumas condições que julgamos fundamentais para que a afirmação da Arqueologia da Arquitectura comece a ter alguma expressão entre nós. Vejamos:
—Começa a existir a noção, entre os mais diversos técnicos que habitualmente intervêm em património, da importância dos registos prévios ao nivel dos paramentos e a sua posterior análise;

-No âmbito Universitário, verificamos também com agrado, a aposta da Unidade de Arqueologia da Universidade do Minho nesta disciplina;

-Em relação as empresas portuguesas, parece-nos surgir, ainda que timidamente, algum interesse na realização deste tipo de estudos, possibilitando a que Instituições como o IPPAR possam brevemente recorrer, de uma forma que desejamos rotineira, a um grupo de técnicos cada vez mais alargado, que possam responder eficazmente às necessidades que se colocam, evitando assim a repetição de intervenções onde não são criadas aquilo que eu chamaria «Condições Mínimas de Segurança Patrimonial».

\section{Bibliografía}

CusTÓDIO, Jorge (1993), Salvaguarda do Património - antecedentes históricos. De Alexandre Herculano à Carta de Veneza. In Dar Futuro ao Passado. Lisboa: IPPAR, p. 33-71.

Lopes, F.; Correia, M. B. (2004), Património Arquitectónico e Arqueológico. Cartas, Recomendaçôes e Convençōes Internacionais. Lisboa: Livros Horizonte,.

Património Arquitectónico e Arqueológico - Legislação. 3 volumes (1930-1993), edição policopiada. Recolha coordenada pela Direcção Regional de Lisboa do IPPAR.

Património Arquitectónico e arqueológico - informar para proteger (1994). Lisboa: Secretaria de Estado da Cultura, Instituto Português do Património Arquitectónico e Arqueológico.

Ramalho, M. De Magalhāes (1994), O Arqueólogo, o Público, o Passado e os seus amantes, al-madam II série, n. ${ }^{\circ} 3$, pp. 56-57.

RAMAlHo, M. DE MAGAlHāes (1996), A arqueologia na Intervenção dos edificios históricos ou a Arqueologia da Arquitectura, al-madam II série, n. ${ }^{\circ}$ 5, pp. 50-56.

Ramalho, M. De Magalháes (2003), Arqueologia da Arquitectura. O método arqueológico aplicado ao estudo e intervenção em património arquitectónico, Revista Estudos/Património, n.o 3, pp. 19-29.

Ramalho, M. De Magalhâes (2005), Potencialidades da Arqueologia da Arquitectura. A experiência do Instituto Português do Património Arquitectónico, Revista Pedra e Cal, Ano VI, n.o 25, pp. 10-11.

Soromenho, M.; VASSAlo E Silva, Nuno (1993), Salvaguarda do Património - antecedentes históricos. Da Idade Média ao século XVIII. In Dar Futuro ao Passado. Lisboa: IPPAR, p. 22-32.

\footnotetext{
19 Exigindo-se, por exemplo, que qualquer intervenção deveria ser antecedida e acompanhada do registo sistemático do edifício, tal como já existe para as intervenções arqueológicas.

20 Refira-se, a este propósito, o projecto de investigação e restauro da catedral de Santa Maria de Vitória-Gasteiz (País Basco) da responsabilidade da "Fundação Catedral Santa Maria» que possibilitou, através de um programa de visitas que se mantém durante os trabalhos, a concretização de um verdadeiro projecto vivo, com relação directa com a comunidade, acabando por transformar aquele monumento numa peça fundamental de todo o processo de reabilitação urbana daquela zona da cidade.
} 